\title{
The Effectiveness of Systemic Approach in Teaching Adjectives
}

\author{
Wiwik Alwiah \\ wiwik.alwiah4@gmail.com \\ Mansur Akil \\ mansurakil@unm.ac.id
}

Andi Muliati

Universitas Negeri Makassar, Indonesia

\begin{abstract}
This study aimed at investigating the effectiveness of the use of the systemic approach to improve students' understanding on adjectives materials related to the use, usage, synonym, antonym, spelling, pronunciation, collocation, meaning, and order. This research employed a quasi-experimental design. The populations were the third-semester students of Muhammadiyah University of Makassar in academic year 2017/2018. The sample consisted of 40 students chosen from two classes by using purposive sampling technique then were divided into two groups, namely experimental and control group. The difference between experimental and control class was based on the teaching technique used during the treatment. While the experimental class was taught by using systemic approach, control class was taught by using the conventional method.The instruments of this research were adjective tests. The data was analyzed by using statistical analysis on SPSS for Windows 20.0 program. As per data, experimental group experienced improvement on their understanding on adjectives in terms of use, usage, meaning, spelling, pronunciation, synonym, antonym, collocation, and order indicated by the posttest mean score (77.1) which was significantly higher than that of the control class (59.7) and the gain of experimental group (31.2) which was higher than control group (17.4). Another supporting indicator is the t-test value which was higher than the t-table value $(4.022>1.75)$. Furthermore, the researcher found that the element of adjective which experienced most significant increase on its mastery happened on the usage, while the lowest one was the collocation. The result of this research indicated that there was significant improvement between experimental and control class. It means that systemic approach that was applied in experimental group can improve the students' mastery on adjectives material. Thus it was concluded that the systemic approach was effective to improve students' on adjectives.
\end{abstract}

keywords: effectiveness, systemic approach, teaching adjectives

\section{INTRODUCTION}

Vocabulary is an inseparable part of any language learning process which consists of the total number of words. In relation to vocabulary, an adjective plays the most important role.Adjective is one of important elements of sentences in every language including English. Using adjectives means that we can express the quality of any person or object. Without adjectives we could not say how any object looks like. According to Martin (2009), adjective as 'describing words' provides information about the qualities of something described in a noun, a noun phrase, or a noun clause. Sannon (2004: 1-77) categorized adjective based on some types such as descriptive ,proper, interrogative, possessive, demonstrative, numeral cardinal, numeral ordinal, indefinite. This research focused on descriptive adjective because it will make students identify some aspects of adjective such as pronunciation, meaning, use, usage, and collocation. 
Nowadays, there are still many students who get difficulty in mastering, memorizing, and identifying adjectives. The students cannot use the adjective in sentences correctlybecause it consists of many categories. Dealing with those problems, the researcher realizes that adjectives must be taught as better as possible and the teachers have to be innovative in designing a teaching process. Thus, one of the approaches which are considered to use in teaching adjectives is systemic approach as alternative solution.

Systemic approach is one of the modern approaches applied by educational researchers that focus on interconnected aspects. Akil (2015) declare that systemic approach which is affects the system as a whole that emphasize holistic point of view in identifying and categorizing. Therefore, the researcher interested to find out the effectiveness of using systemic approach in teaching adjectives to the third-semester students of Muhammadiyah University of Makassar. The discussion of systemic approach in this research is mainly based on Akil's (2015) theory. It focuses on the use of systemic approach which was covered nine inter-related elements: spelling, pronunciation,meaning, use, usage, synonym, antonym, collocation, and order.

\section{RELATED LITERATURE}

\section{Systemic Approach}

\section{Definition of Systemic Approach}

There are several opinions about systemic approach proposed by some experts. Akil (2015) states that systemic approach is an approach considers to the holistic point of view that covers the entire elements of a system. All elements of the system should intersect, interrelate, and interacts one another. If any element misses any of these systemic features, the element should be excluded from the system, and otherwise, it will jeopardize the system. Moreover,Kaufman (2012) claims systemic approach asan approach affects everything in the system.Systemic approach is also defined by Fogarty (2015) as the approach that describes something that happens or exists throughout a whole system. in addition, Al- Bhery et al. (2010:407) declares that systemic approach depended on the concept of the system that meant a set of things that accumulated in a certain field and had several interrelations that aim at achieving specific goals. Therefore, the researcher concludes that systemic approach is an approach depended on the concept of system that emphasize the regularity and holistic point of view in identifying and categorizing adjectives to make the learners easily to master them.

\section{Teaching adjective by using systemic approach}

Systemic approach emphasizes the regularity and holistic point of view in doing or learning something. This approach consists of three main points, namely intersection, interaction, and interrelation (Akil, 2015). Intersection refers to all elements of a system (everything) present at the same time. Interaction means all elements of a system interacts one another (functional). Then, interrelation implies all interactions of the elements support the achievement of the goal of the system (relevant). The following figure describes the concept of systemic approach related to adjective: 


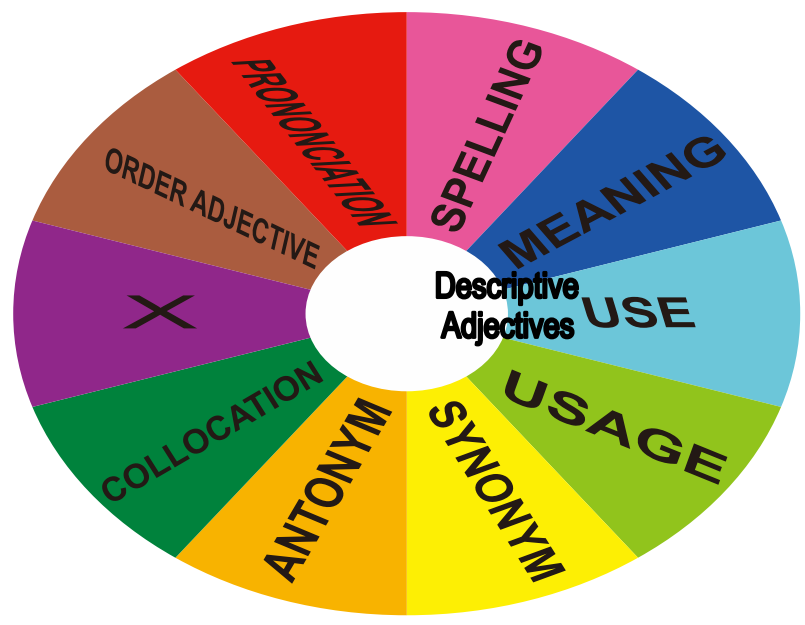

Figure 2.1

The chart of systemic approach (Akil, 2015)

\section{Aspects of teaching adjective by using systemic approach}

There are nine aspects which must be included in teaching adjectives by using systemic approach. Those are spelling, pronunciation,meaning, use, usage, synonym, antonym, collocation, and order. These aspects cover 3 points of systemic approach; intersection, interaction and interrelation. The following are the definition of those aspect:

1) Spelling

: The forming of words from letters according to accepted usage

2) Pronunciation

: The way to pronounce a word

3) Meaning

: The thing one intends to convey especially by language

4) Use

: A method or manner of employing or applying something

5) Usage

: The way in which words and phrases are actually used ( as ina particular form or sense) in a language community

6) Synonym

: One of two or more words or expression of the same language that have the same or nearly the same meaning in some or all senses

7) Antonym : : A word of opposite meaning

8) Collocation : A particular combination of words

9) Adjective order : The customary order in which two or more adjectives appear in front of a noun

\section{The concept of adjectives}


Adjectives add something extra to the meaning of the nouns which they qualify. They are classified into umpteen kinds in accordance with their function.

a. Definition of adjective

Sannon (2004:47) declared that adjective has function to describe or modify a noun. In addition, Nair (2002) also states that adjectives limit a noun. It makes a noun more explicit and uses to limit the scope of general term. Therefore, adjective as 'describing words' provide information about the qualities of something described in a noun, a noun phrase, or a noun clause.

\section{b. Types of adjectives}

Sannon (2004: 1-77) divided adjective based on their types into eight categories such as descriptive, proper, possessive , demonstrative, interrogative, numeral cardinal, numeral ordinal and indefinite.

\section{A. Descriptive adjective}

The descriptive adjectives are used to express the size, color, or shape of a person, a thing, animal, or a place. They are used to provide more information to a noun by describing or modifying it. They also usually express things which are observable through the five senses (touch, taste, sight, smell, and sound). Those adjectives are added to the words for identifying, qualifying, distinguishing, and giving the essential nature of the words. Therefore, a descriptive adjective adds meaning to the noun that it modifies. Additionally, it also describes a noun in detail by giving an attribute to that particular word.

\section{RESEARCH METHOD}

This research applied quasi-experimental design. This research design was employed by the researcher to collect and analyse the data in order to get answer from the research questions. The population was 276 third-semester students of Muhammadiyah University of Makassar in academic year 2017/2018 which were divided into ten classes. 40 students from two classes (E and F class) were selected as the sample of this research by using purposive sampling technique. They were divided into two groups, namely experimental and control group. The experimental class was taught by using systemic approach, while control class was taught by using the conventional method. In collecting data, the researcher used adjective tests as the instrument. It included 70 items that consist of nine parts which was refers to are spelling, pronunciation,meaning, use, usage, synonym, antonym, collocation, and order. Then, the data was analyzed by using statistical analysis on SPSS for Windows 20.0 program.

\section{FINDINGS AND DISCUSSION}

The findings of this research deal with students' classification score on students' score in adjectives' components, the mean score, standard deviation and t-test of pretest and posttest. These findings are described as follows:

\section{Students' Classification Score}

a. The Mean Score and Standard Deviation 
Mean score and standard deviation of students' pretest and posttest presented in the following table:

Tabel. 1Mean score and standard deviation of both classes in pre-test and post-test

\begin{tabular}{|c|c|c|c|c|}
\hline \multirow{2}{*}{ Test } & \multicolumn{2}{|c|}{ Experimental Group } & \multicolumn{2}{c|}{ Control Group } \\
\cline { 2 - 5 } & Mean & $\begin{array}{c}\text { Standard } \\
\text { Deviation }\end{array}$ & Mean & $\begin{array}{c}\text { Standard } \\
\text { Deviation }\end{array}$ \\
\hline Pre-Test & 45.9 & 0,25 & 42.2 & 0,37 \\
\hline Post-Test & 77.1 & 0,24 & 59.7 & 0,34 \\
\hline
\end{tabular}

Table 1 shows the mean score and standard deviation of both experimental and control group in pre-test and post-test. For experimental group, the mean score was 45.9 and standard deviation was 0,25 in pre-test. In post-test, there is a significant improvement of the mean score (77.1) and standard deviation $(0,24)$. On the other hand, the mean score for the control group was 42.2 and standard deviation was 0,37 in pre-test. While in post-test, the mean score was 59.7 and standard deviation was 0,34 .

a. T-Test Value of Students.

For the level significance $(\mathrm{a})=0,05$ and degree of freedom $(\mathrm{df})=(\mathrm{N} 1+\mathrm{N} 2-2=38)$, the value of $\mathrm{t}$-table is 2.024 . The following table showed the result of the calculation.

Table.2 T-Test Value of Student's

\begin{tabular}{|c|c|c|}
\hline Group & T-test & T-table \\
\hline N-Gain & 4.022 & 2.024 \\
\hline
\end{tabular}

Based on the table 2 above, the t-test value was 4.022 and $t$-table value was 2.024. It shows that $\mathrm{t}$-test value was higher than $\mathrm{t}$-table value $(4.022>2.024)$. It means that there was significantimprovement between experiment and control group. This result indicated that systemic approach significantly was improving the students' ability in learning adjectives.Thus, the null hypothesis (H0) is rejected and alternative hypothesis (H1) is accepted.The alternative hypothesis said that there was significant improvement of students' adjectives after using systemic approach.

The description of the student' understanding in learning adjectives covering some elements like use, usage, synonym, antonym, spelling, meaning, collocation, pronunciation, and order.

\section{Students' Classification Score in Writing Components}

The following table shows the mean score and standard deviation of students' score in pretest and post-test. The scores are presented based on nine elements namely use, usage, synonym, antonym, spelling, meaning, collocation, and adjective order. 
Table. 3 Mean scores and standard deviations of students' pre-test and post-test score in term of nine adjectives' elements

\begin{tabular}{|c|c|c|c|c|c|c|}
\hline \multirow{2}{*}{ No } & \multirow{2}{*}{\multicolumn{2}{|c|}{ Adjective's Elements }} & \multicolumn{2}{|c|}{$\begin{array}{c}\text { Experimental } \\
\text { Group }\end{array}$} & \multicolumn{2}{|c|}{ Control Group } \\
\hline & & & $\begin{array}{l}\text { Mean } \\
\text { Score }\end{array}$ & $\begin{array}{l}\text { Standard } \\
\text { Deviation }\end{array}$ & $\begin{array}{l}\text { Mean } \\
\text { Score }\end{array}$ & $\begin{array}{l}\text { Standard } \\
\text { Deviation }\end{array}$ \\
\hline \multirow{2}{*}{1} & \multirow{2}{*}{ Spelling } & Pre-test & 45.5 & 1.605 & 47.5 & 1.832 \\
\hline & & Post-test & 80 & 1.451 & 63 & 1.218 \\
\hline \multirow{2}{*}{2} & \multirow{2}{*}{ Pronunciation } & Pre-test & 48 & 1.604 & 39.5 & 1.877 \\
\hline & & Post-test & 79.5 & 1.504 & 54.5 & 1.791 \\
\hline \multirow{2}{*}{3} & \multirow{2}{*}{ Meaning } & Pre-test & 46 & 1.635 & 42 & 1.908 \\
\hline & & Post-test & 75 & 1.147 & 58 & 1.542 \\
\hline \multirow{2}{*}{4} & \multirow{2}{*}{ Use } & Pre-test & 42 & 2.016 & 42.5 & 1.860 \\
\hline & & Post-test & 75 & 1.147 & 62.5 & 1.293 \\
\hline \multirow{2}{*}{5} & \multirow{2}{*}{ Usage } & Pre-test & 42 & 1.936 & 41.5 & 1.667 \\
\hline & & Post-test & 79 & 1.373 & 61 & 1.373 \\
\hline \multirow{2}{*}{6} & \multirow{2}{*}{ Synonym } & Pre-test & 45.5 & 1.605 & 39 & 2.024 \\
\hline & & Post-test & 80 & 1.451 & 62.5 & 1.517 \\
\hline \multirow{2}{*}{7} & \multirow{2}{*}{ Antonym } & Pre-test & 49.5 & 1.663 & 37 & 1.838 \\
\hline & & Post-test & 75 & 1.147 & 56 & 1.635 \\
\hline \multirow{2}{*}{8} & \multirow{2}{*}{ Collocation } & Pre-test & 49.5 & 1.669 & 42.5 & 1.943 \\
\hline & & Post-test & 75 & 1.147 & 56.5 & 1.755 \\
\hline \multirow{2}{*}{9} & \multirow{2}{*}{ Adjective Order } & Pre-test & 48 & 1.576 & 48 & 1.981 \\
\hline & & Post-test & 75 & 1.144 & 63 & 1.218 \\
\hline
\end{tabular}

Based on statistical data above, the result of the research showed that systemic approach is effective to use in teaching adjectives. It was proven by the result of data analysis of pretest and post-test. It showed that the students' post-tests had higher score than pre-tests in term of all adjective's elements namelyspelling, pronunciation, meaning, use, usage, synonym, antonym, collocation, and adjective order. In other words, the use of systemic approach in teaching adjective can improve students' adjectives mastery which includesnine-interrelated elements of adjectives that were taught in the treatments. The researcher taught the whole elements related to adjectives systemically. Thus, the students could know how to spell and pronounce the words. Moreover, they were able to know the meaning of the words, then students know the synonymy and antonym of the word and understand when and how to use the word in the sentence in different context.

Theoretically, this finding proved the theories that related to systemic approach. Akil (2015) claims that the success of a system to achieve its goal is determined by intersection, interrelation, and interaction of its elements. In this approach, all interrelated elements of adjectives are intersected, interrelated and interacted one another to make the subject is totally clear for students. 


\section{CONCLUSION AND SUGGESTION}

The use of systemic approach in teaching English adjectives helps the first semester of students' Muhammadiyah University of Makassar mastering English adjectives. It was proven with the total higher mean score of the students post-test in experimental group (77.1) than the control class (59.7). It also proven by the gain score of experimental group (31.2) was higher than control group (17.4). In addition, t-test value was higher than t-table value $(4.022>2.024)$, then it indicates that the whole elements of adjectives should be taught systemically because the completeness of the materials determines the effectiveness of learning process. In this research, the researcher found that the highest element in systemic approach was usage and the lowest one was collocation.

For suggestion, this research can be used as additional reference for English lecturers at Muhammadiyah University of Makassar. It is suggested to use systemic approach in teaching adjectives to help students understanding adjectives faster and better. Systemic approach helps the students to master and comprehend adjectives because they are taught all interrelated elements related to adjectives. In addition, this approach makes the students' more active in the classroom and motivates them to study English, especially adjectives. The students are supposed to learn adjective as one of the alternative to add their vocabulary and to learn about nine inter-related elements namely use, usage, synonym, antonym, meaning, pronunciation, spelling, collocation and order. This study can lead other researchers conduct a research with the same approach to use it in the different element of English to know whether or not systemic approach theory can be function to improve students' ability in other element of English or in the different subject.

\section{REFERENCES}

Akil, Mansur. (2015). Systemic Approach (SA) to Curriculum Development: Application and Implication of Systems Thinking in Curriculum Development. Makassar: State University of Makassar.

Al-Bhery, et al. (2010).Effects of Using the Systemic Approach on Learning Some Fencing Skills for Junior Fencers. Egypt: World Journal of Sport Sciences 3.

Fogarty, Mignon. (2015). Systemic or Systematic?Retrieved on February 1 ${ }^{\text {st }}, 2016$ from: http://systemic\%20approach/save\%20as/systematic_systemic.htm.

Kaufman, Roger. (2012). System Approach, Systems Approach, Systematic Approach, and Systemic Approach-Like Cousins, They Are Related but Not the Same. Retrieved on October $25^{\text {th }}, 2015$ from:http://www.performancexpress.org/2012/11/systemapproach systems-approach-systematic-approach-and-systemic-approach-likecousins-they-are-related-but-not-the-same/

Martin. (2009). Easy language series: Verbs \& adjectives. Amazon.com

Nair, Sreedevi. K. (2002).Learn to Speak and Write Confidently in English. India: Kottayyam Kerala state.

Sannon. (2004). New English Grammar and Exercises for ESL Students.Bloomington :United states Of Amerika Bloomington 